\title{
SUPERSQUIRT: DYNAMICS OF THE GULF OF TEHUANTEPEC, MEXICO
}

\author{
By Eric D. Barton, Maria L. Argote, \\ Juan Brown, P. Michael Kosro, \\ Miguel Lavin, Jose M. Robles, \\ Robert L. Smith, Armando Trasviña, \\ and Hector S. Velez
}

\begin{abstract}
$\mathrm{T}$ HE LAST TWO DECADES have seen a continuing effort to observe and model the response to wind forcing in the coastal ocean along eastern boundaries of ocean basins. The emphasis of research has developed through several stages including: studies of the large-scale steady state, the transient responses in localized areas, the alongshore propagation of wind-induced disturbances, and most recently the evolution of cold filaments extending offshore from the coastal upwelling zone into the open ocean. Frequently associated with such filaments is a strong jet-like current referred to as a "squirt" (Ramp et al., 1991). One interesting area that has been neglected by sea-going oceanographers with modern instrumentation is the Gulf of Tehuantepec. There, large negative temperature anomalies extend several hundred kilometers seaward as a result of offshore, rather than alongshore, winds (Fig. 1). By comparison with the size of the typical upwelling-filament temperature and current structure, they might be termed "Supersquirts." Significant chlorophyll anomalies seen in Coastal Zone Color Scanner (CZCS) imagery indicate enhanced primary production in the same region.

The Gulf, which is situated off the Pacific coast of southern Mexico, is subjected to intermittent forcing by an intense, offshore wind jet during the winter months (first documented by Hurd, 1929). The jet is generated when atmospheric pressure rises to high levels over the Gulf of Mexico as a result of cold outbreaks from the North American continent. At the same time, pressure over the Pacific remains low (Fig. 1a). The mountains of
\end{abstract}

E.D. Barton, H.S. Velez, University College of North Wales, School of Ocean Sciences, Menai Bridge, Gwynedd LL59 5EY, United Kingdom. M.L. Argote. M. Lavin, J.M. Robles, A. Trasviña, Centro de Investigacion Cientifica y Education Superior, Ensenada, B.C., Mexico. J. Brown, Ministry of Agriculture, Fisheries and Food, Fisheries Laboratory, Lowestoft, Suffolk NR33 OHT, United Kingdom. R.L. Smith, Oregon State University, College of Oceanography, Corvallis, OR 97331, USA. the Sierra Madre range, typically over $1500 \mathrm{~m}$ high, separate the colder, high-pressure air on the Atlantic side from that over the Pacific Ocean. At the Isthmus of Tehuantepec, the Chivela Pass, some $40 \mathrm{~km}$ in width and $250 \mathrm{~m}$ in maximum elevation, allows the cool, dry northern air to escape into the Pacific as a fierce, short-lived wind jet that rushes directly offshore. Similar, if weaker, winds enter the Pacific over the Nicaraguan lakes and Panama.

The wind, known locally as a "Norte", influences conditions for several hundred kilometers out to sea. Typical northerly events last 3 or 4 days and may attain speeds $>20 \mathrm{~m} \mathrm{~s}^{-1}$. The strong pulses of offshore wind, which occur at roughly ten-day intervals, invoke a strong sea-surface response readily detectable by satellite. Surface temperatures from infra-red imagery during a Norte event were reported by Stumpf (1975) to be as much as $8^{\circ} \mathrm{C}$ cooler than surrounding undisturbed waters. Strong et al. (1972) showed from visible-band imagery that a comma-shaped region of increased surface roughness was produced by the wind jet. Both temperature and roughness anomalies were similar in spatial extent. Roden (1961), in an analysis of the historical records of ship drift and temperature in the Gulf, suggested that much of the surface cooling could be attributed to upwelling induced by the curl of the wind stress. Vertical mixing also is expected to be of major importance; however, the few in situ observations available (Blackburn, 1962) are insufficient to distinguish between the two processes.

Other satellite sea-surface temperature studies (Stumpf and Legeckis, 1977; Apel, 1980), have shown that anticyclonic eddies, with diameters of several hundred kilometers, form off the Gulf as a result of the winter wind. The features were reported to migrate offshore at the group speed of nondispersive baroclinic Rossby waves. More recently, drifter observations of anticyclonic, westward-migrating eddies in the North Equatorial Current have been reported by Hansen and Maul (1991). These apparently originate in the eastern
. . . a fierce, short-

lived wind jet the

rushes directly

offshore. 


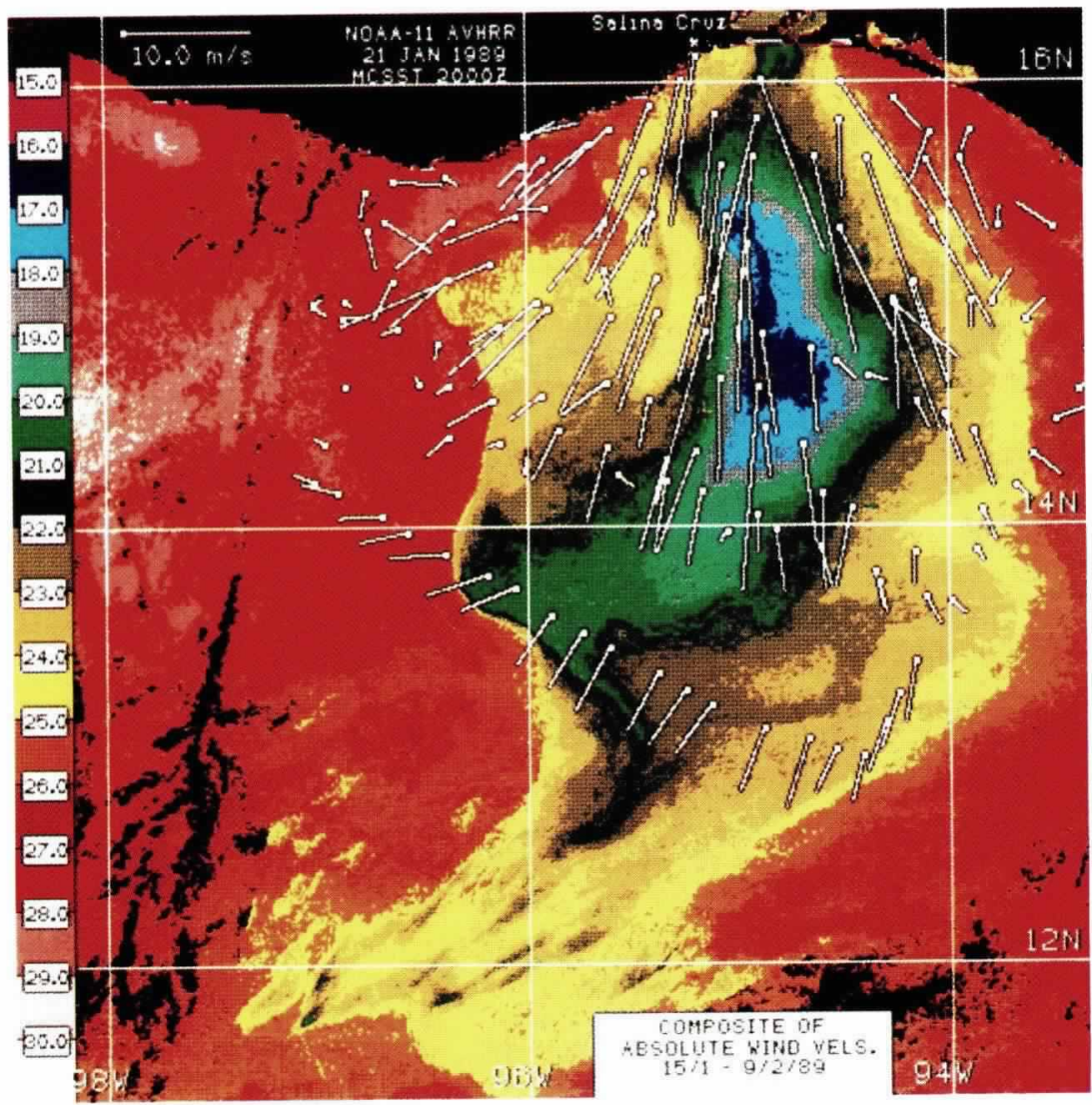

Fig. 1: Sea-surface temperature image of the Gulf of Tehuantepec 21 January 1989. The onset of a Norte wind event has cooled surface waters in the central Gulf by $\sim 8^{\circ}$ C. Overlaid on the figure is a composite of ship wind observations, averaged over the observation period.

Tropical Pacific, but any relation to the Gulf of Tehuantepec eddies is not established.

Models of the Gulf include that of Clarke (1988), who developed a linear $1 \frac{1}{2}$-layer analytical model. He assumed the wind had the form of an inertial jet, whose clockwise circular trajectory produced an anticyclonic eddy of the same radius. Antisymmetric pycnocline elevations were predicted with depression occuring to the western side of the jet. A second model, also $1 \frac{1}{2}$-layers but including numerical and nonlinear treatments, was driven by a straight wind jet perpendicular to the coast (McCreary et al., 1989). In this case, a cyclonic eddy initially spun up to the east of the wind jet was quickly damped by entrainment from the lower layer, while an anticyclonic eddy to the west of the wind persisted. On cessation of wind forcing, the model indicated the latter eddy would expand in diameter, weaken and propagate out of the generation region.

Detailed in situ observations of the Gulf during periods of strong wind have been lacking. Even basic features of the Gulf forcing and response remain to be determined: for example, the spatial structure of the wind jet, the relative importance of vertical advection and mixing (in cooling the surface layers), and the horizontal circulation during and after an event, particularly in relation to the eddy dynamics.

This article presents an overview of the results of an international, cooperative field program completed during early 1989 in the Gulf of Tehuantepec. The overall aims of the experiment were to observe the spatial and temporal variability of the wind field over the Gulf, and its consequent effect on the hydrographic structure and circulation. Participating investigators were from the United Kingdom, Mexico, and the United States. A synopsis of the experimental results has been published in Spanish (Lavín et al., 1992).

\section{The Experiment}

Two ships, the Mexican research vessel $E /$ Puma and the U.S. research vessel Wecoma, worked together in the Gulf of Tehuantepec between 7 January and 10 February 1989. Three shallow moorings monitored flow in the inner Gulf and three deep $(\sim 4000 \mathrm{~m})$ moorings, with $300-\mathrm{kHz}$ Acoustic Doppler Current Profilers (ADCP's) looking upward from $120 \mathrm{~m}$, were deployed along a line $200 \mathrm{~km}$ offshore and perpendicular to the axis of the wind jet. Adjacent meteorological buoys, below which were suspended thermistor chains, recorded wind speed and direction, air and sea-surface temperature, and Conductivity-temperature-depth (CTD) profiling was carried out over the continental shelf of the Gulf by El Puma while hydrographic sampling, including chlorophyll fluorescence, was undertaken farther offshore by the Wecoma using both CTD profiling and transects with SeaSoar. The latter is a towed undulating vehicle housing a CTD, which allows continuous along track profiling down to $300 \mathrm{~m}$. In effect, this produces a CTD profile every $\sim 2 \mathrm{~km}$ at the optimum towing speed of $\sim 8$ knots. Simultaneous sampling with a $150-\mathrm{kHz}$ vessel-mounted ADCP was carried out to provide matched hydrographic and velocity data sets. Almost daily advanced very high resolution radiometer (AVHRR) sea-surface temperature images were obtained from the United States Naval Ocean Research and Development Activity (NORDA) at Stennis Space Center.

\section{Wind Forcing}

Time series of hourly averaged wind observations measured on board Wecoma (Fig. 2c) show a Norte event occurred on 21-22 January. The ship observations differ at times from measurements at the individual meteorological buoys, because the vessel was sampling in other more sheltered areas of the Gulf. The predominant direction of the wind was almost directly southward over the central Gulf, except during brief episodes of weak wind.

The sampling period of Wecoma was characterized by wind speeds which weakened gradually from an initial value of $\sim 10 \mathrm{~m} \mathrm{~s}^{-1}$ (Fig. 2c) to almost zero early on 21 January, after which speed 


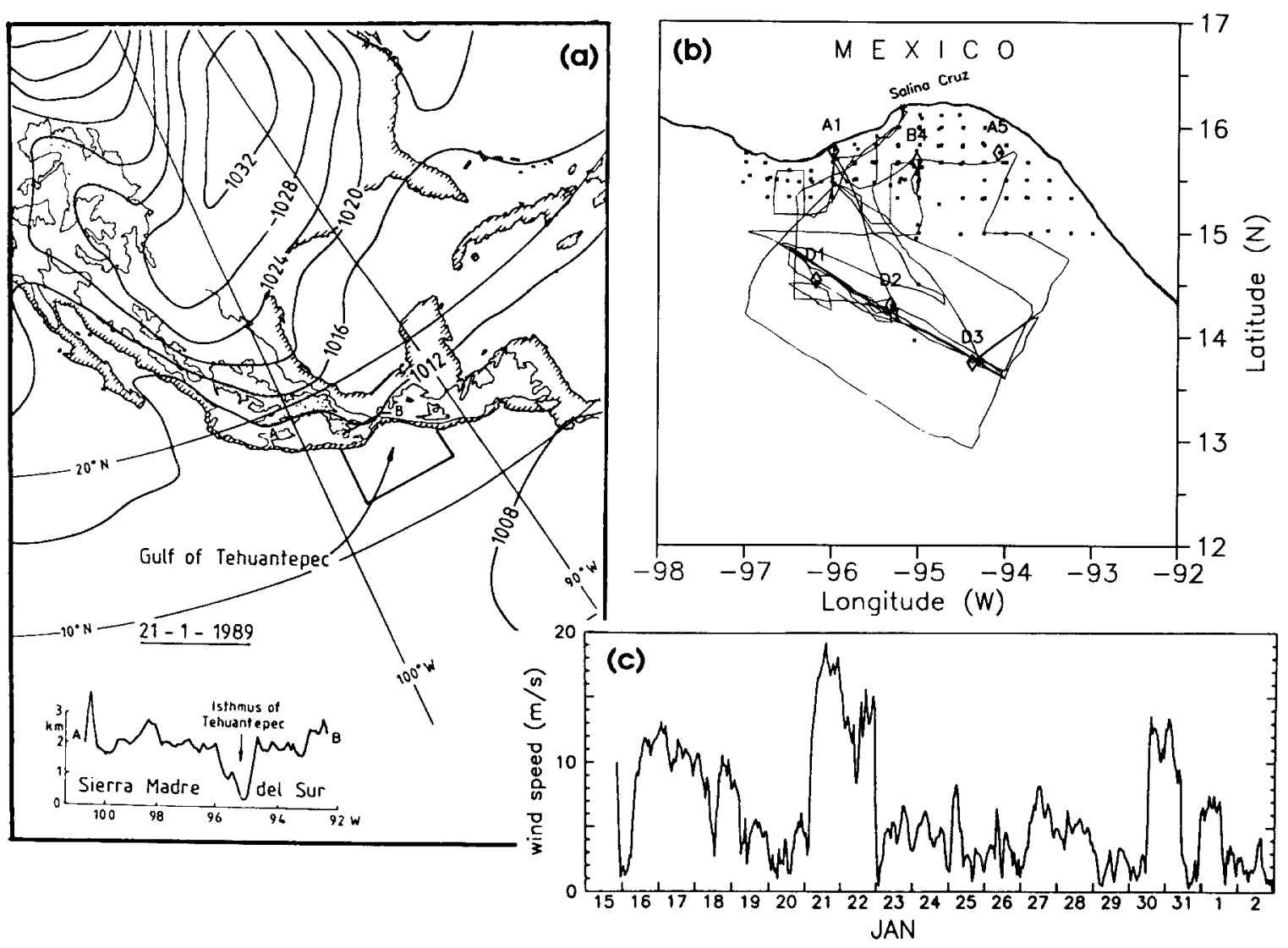

Fig. 2: (a) Sea-level pressure distribution over central America 21 January 1989. Higher pressure associated with cold outbreak is retained to the Atlantic side of the continental mountain ranges. The Nortes are forced through the gap at the Isthmus of Tehuantepec, sketched in the inset. (b) Cruise track for Wecoma (-). CTD station positions for Puma (-), and mooring positions (A1, B4 and A5 shelf moorings; D1, D2, D3 deep ADCP and meteorological moorings ( $(3))$. (c) Wind speed record from Wecoma. The Norte event started on 21 Januar:

increased within a few hours to gusts in excess of $25 \mathrm{~m} \mathrm{~s}^{-1}$ and hourly averages close to $20 \mathrm{~m} \mathrm{~s}^{-1}$. The Norte event lasted $<3$ days before wind speeds fell to values $\sim 5 \mathrm{~m} \mathrm{~s}^{-1}$. A brief resurgence of the wind occurred on 30-31 January but, after this time, winds remained weak almost until the end of the cruise. On 8-9 February, a major northerly wind event commenced, making entry to the port of Salina Cruz difficult.

The effect of the wind event on 21 January, despite its relatively moderate intensity, was dramatic (see Fig. 1). The sea-surface temperature (SST) map derived from AVHRR imagery shows a well defined cooling of the surface extending some $400 \mathrm{~km}$ seaward from the shoreline. The anomalously cold region was $\sim 200 \mathrm{~km}$ in width. Its western boundary was delimited by stronger temperature gradients than its eastern boundary, and minimum surface temperatures were found $\sim 150 \mathrm{~km}$ offshore. Overlaid on the image is a composite of wind vectors observed from both ships and averaged by location. The composite includes winds from calm periods and sites, but is dominated by the observations of strong winds. A spreading of the wind jet with increasing dis- tance from the coast is apparent. The greatest temperature anomalies occurred within the zone of strongest winds.

\section{The Gulf Response}

\section{Sea-Surface Temperature}

The state of the Gulf on 20 January, immediately before the wind event, is seen in Figure 3a. Despite winds of $10 \mathrm{~m} \mathrm{~s}^{-1}$ during the early part of the Wecoma cruise, the SSTs of 20 January had returned to the relative uniformity typical between wind events, showing only a weak anomaly in the central Gulf. Much of the center and southeast of the Gulf was obscured by clouds at that time. Highest temperatures were seen in the west, reaching $29^{\circ} \mathrm{C}$. The coolest water at the coast was displaced almost $100 \mathrm{~km}$ west of the head of the Gulf. Near-surface current vectors measured by the shipboard ADCP are superimposed on the image along the ship track. Currents, weak across the Gulf, were directed southwestward in the west and northeastward in the east.

Within hours of the start of the wind event on 21 January, surface temperatures in the central Gulf dropped by as much as $8^{\circ} \mathrm{C}$ (Fig. 1). The
$W_{\text {ithin hours of the }}$

start of the wind event

. . . surface

temperatures . . .

dropped by as much

as $8^{\circ} \mathrm{C}$. . . 


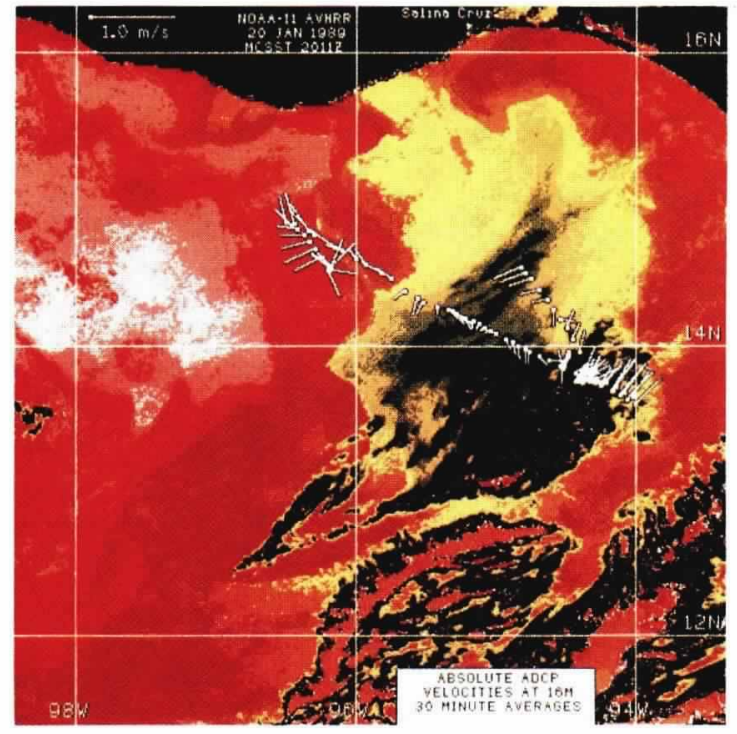

(a)

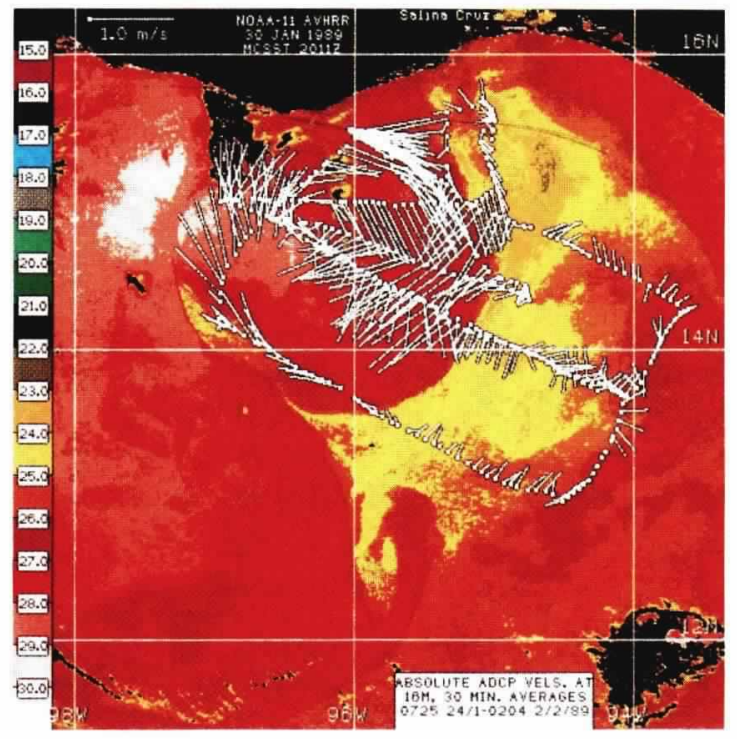

(c)

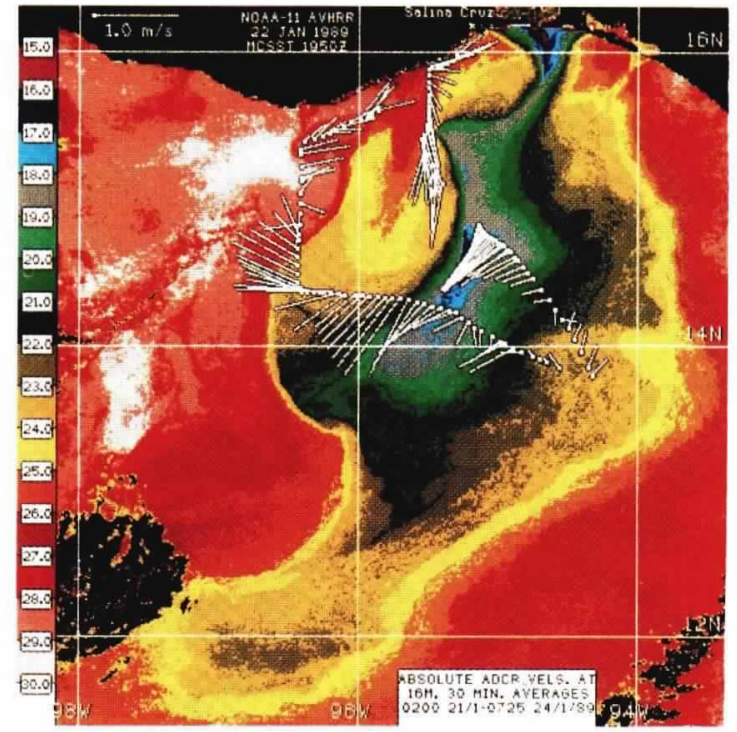

(b)

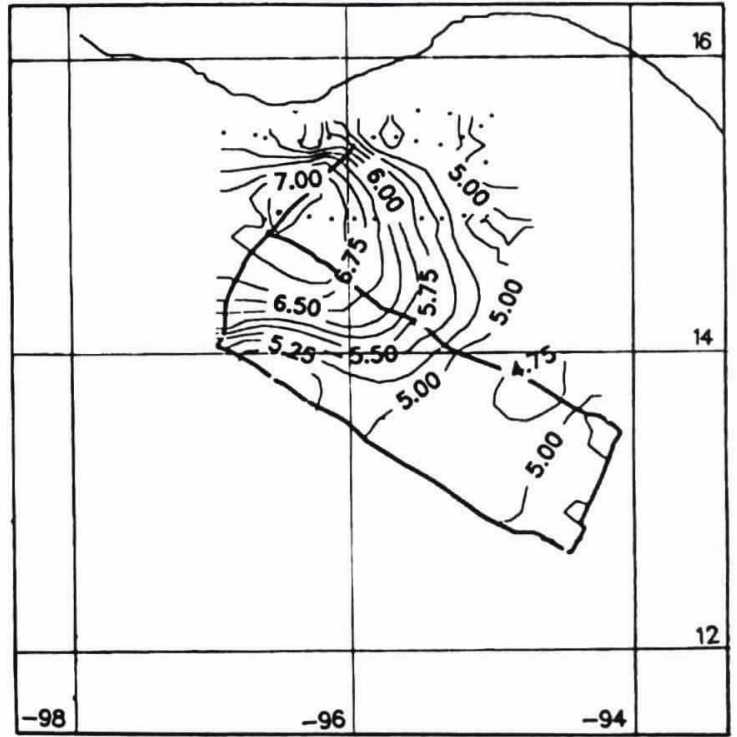

(d)

Fig. 3: (a) Sea-surface temperature image of 20 January before the wind event. Current vectors at $22 \mathrm{~m}$ depth from the Wecoma ADCP are overlaid. (b) Same records for 22 January, following the event. (c) Same records for 30 January, a week later. Note the strong anticyclonic eddy. (d) Dynamic topography of the sea-surface relative to 250 dbar for 27 to 31 January.

\section{. . a weak}

chlorophyll maximum and a . . . mixed region at $80 \mathrm{~m}$ depth

[were] compatible with frontal subduction . . . relative humidity over the Gulf dropped from 95 to $55 \%$ as the cool, dry air spread out from the coast. ADCP observations (not shown in this image) indicated a rapid acceleration of southwestward flow in the central Gulf to speeds approaching $1 \mathrm{~m} \mathrm{~s}^{-1}$. The strong thermal front to the west of the cold anomaly showed a cusp-like formation with a wavelength of $150 \mathrm{~km}$. To the east, the temperature gradient was much weaker. The most intense cooling was located in the central Gulf, slightly north of mooring D2. Cooling was evident in the very head of the Gulf but at this stage was not nearly as intense as offshore.

The SST image of the following day, 22 January, shows persistence of the cold plume and its major features (Fig. 3b). Some slight weakening of the temperature anomaly in the central Gulf was evident, while at the coast temperatures continued to fall, possibly as a result of upwelling over the shelf. The ADCP vectors overlaid on this map (composites for the period 21-24 January) show a weak northward flow on the eastern flank of the anomaly. Strong offshore currents occurred in the central Gulf, coincident with the western boundary of the cold anomaly. There was some evidence of convergent flow toward this strong temperature front. The presence of a weak chlorophyll maximum and a coincident vertically mixed region at $80 \mathrm{~m}$ depth west of the front was compatible with frontal subduction down isopyc- 
nal surfaces (Trasvin̄a, 1991). Further to the west, the form of the vectors suggested an anticyclonic eddy centered near $15^{\circ} \mathrm{N}, 96^{\circ} \mathrm{W}$ and associated with a cusp formation in the temperature boundary. Near shore, warmer surface waters flowed strongly from the west toward the head of the Gulf. A proportion of this flow was entrained southeastward into the eddy circulation as a warm tongue.

Following the end of the wind event, relatively calm conditions persisted for a week or so. The image of 30 January (Fig. 3c) shows a return to temperature conditions similar to those before the wind event, with minimum temperatures $\sim 23^{\circ} \mathrm{C}$. This occurred as a result of the combined effect of horizontal mixing, direct solar heating, and warmer water from the eddy spreading southwestward over the previously cool surface mixed layer.

The most notable difference from earlier conditions is the presence of a large anticyclonic eddy in the western Gulf. Cool water was entrained around its southwestern flank and northward toward the coast. Composite ADCP vectors for the period 24 January to 2 February, superimposed on the image, emphasize the form of the strong 250-km-diameter feature. Azimuthal velocities exceeded $1 \mathrm{~m} \mathrm{~s}^{-1}$, despite the much reduced winds during this period. Farther east, weak currents flowed essentially northeastward toward the upper Gulf.

The dynamic topography of the sea-surface relative to $250 \mathrm{dbar}$, derived from a combination of El Puma and Wecoma sections between 27 and 31 January (Fig. 3d), reveals a surface-elevation anomaly of $>20 \mathrm{~cm}$ associated with the eddy. The major characteristics of the topography show a strong correspondence with the ADCP current field when overlaid on the satellite image of 30 January. Sampling did not extend far enough westward to enable closure of all the dynamic height contours. In the southeast, the sea-surface slope was reversed in the region of onshore, northwestward flow.

\section{Central Gulf Response}

A SeaSoar transect across the mooring line indicates the spatial structure of the response to the wind event (Fig. 4a). The section commenced as the wind began to abate on 23 January and passed within $10 \mathrm{~km}$ of site D2. By that time, near-surface thermistor chain records at D2 were already showing recovery from the minimum temperatures during the event. Nevertheless, the effect of intense vertical mixing in the central region, below the core of the wind jet, was evident from the
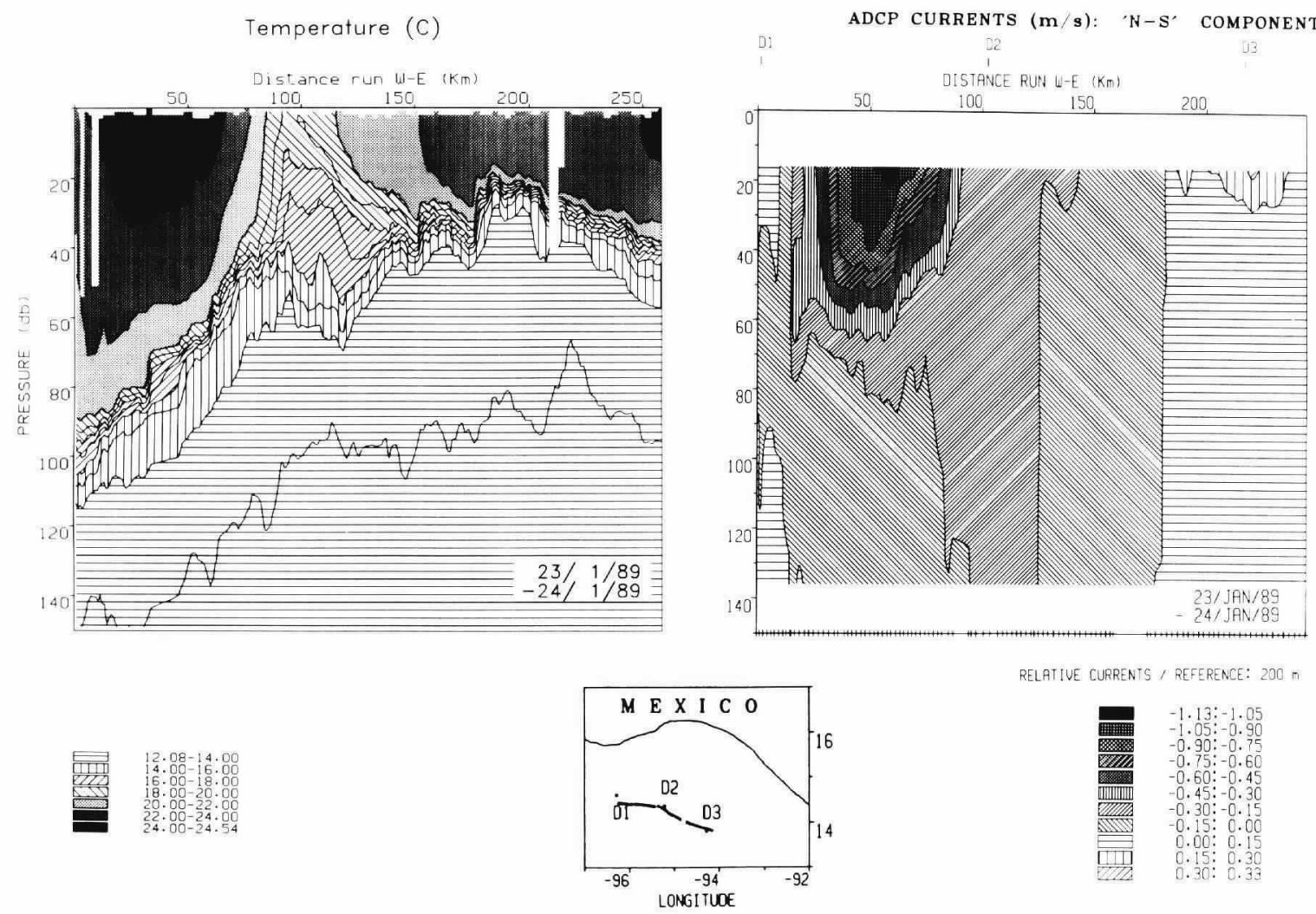

RELATIUE CURRENTS / REFERENCE: $200 \mathrm{n}$

Fig. 4: Sections across the Gulf on 23-24 January, shortly after the wind event. (a) Temperature from SeaSoar; (b) Shipborne ADCP velocity (- southward, + northward). The ship track is shown by inset. Note the offshore baroclinic jet associated with the western temperature front and the weak northeastward barotropic flow in the eastern side. 
A

nearshore

confluence. . . as

in to compensate the

drop in sealevel . coastal waters flowed

spreading of the thermocline and decreased surface temperature. The thermocline structure showed a strong asymmetry across the Gulf, bowed downward in the west and upward in the east. The maximum thermocline elevation occurred not under the strongest wind but on its cyclonic flank, corresponding to the position of maximum wind-stress curl. During the continued period of weaker winds, surface warming re-established the strong thermocline throughout the central Gulf. The thermocline deepened by $\sim 50$ $\mathrm{m}$ in the west during and following the event, consistent with spin up of the anticyclonic eddy.

The corresponding section of Wecoma ADCP current component, normal to the transect, shows the baroclinic structure of the flow in the western Gulf following the event (Fig. 4b). Current speeds were in excess of $1.4 \mathrm{~m} \mathrm{~s}^{-1}$ near surface but fell off rapidly with depth to near zero values below $100 \mathrm{~m}$. The region of strongest velocity and vertical shear corresponds to the enhanced horizontal
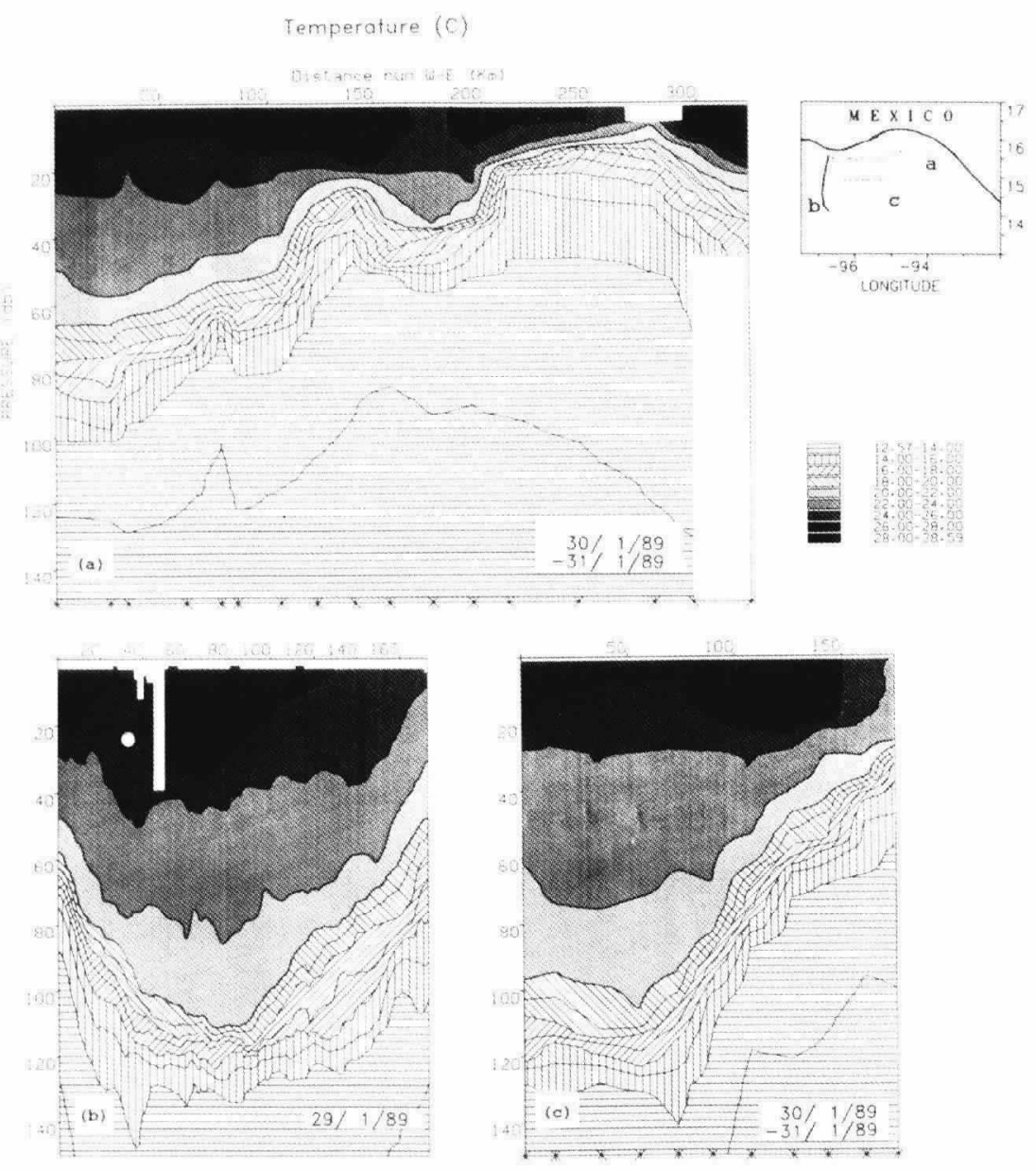

Fig. 5: Sections of temperature across the anticyclonic eddy. (a) CTD section across head of the Gulf shows main eddy in the west and small cyclone in center. (b) Meridional SeaSoar crossing of eddy showing entrainment of warm coastal water from north. (c) CTD section into center of eddy parallel to and simultaneous with (a). The ship track and CTD station positions are shown by inset. temperature gradients on the anticyclonic side of the wind jet. This marks the eastern boundary of the anticyclonic eddy, as visible in the image of 22 January (Fig. 4b). On the eastern side of the Gulf, flow was essentially barotropic, weakly northward throughout the water column. Subsequent transects showed an eastward extension of the anticyclonic eddy toward the central Gulf with undiminished baroclinic velocity structure.

A nearshore confluence in the head of the Gulf was obvious in current records from moorings A 1 and A5, as coastal waters flowed in to compensate the drop in sea level at Salina Cruz. However, coastal currents at both sides halted almost completely during the peak of the event, possibly because the alongshore pressure gradient was balanced temporarily by the frictional drag of the wind. At moorings B4 and D2, on the axis of the wind jet, the flow generally was parallel to the local temperature fronts. Changes of flow direction at B4 coincided with changes in orientation of the temperature front on the western flank of the cool anomaly. In the west, an overall westward flow at mooring D1 was related to the position of the anticyclonic eddy. In the east at D3, the northward flow evident previously in the ADCP section persisted throughout the event, modulated by an inertial oscillation (local period $\sim 50 \mathrm{~h}$ ), also apparent in the D2 record.

\section{The Anticyclonic Eddy}

\section{Three-Dimensional Structure}

The dynamic structure of the eddy was investigated by a number of crossings between 28 and 31 January. As El Puma sampled with a CTD from east to west across the mouth of the gulf (Fig. 5a), Wecoma completed a northeastward SeaSoar transect bisecting the eddy (Fig. 5b). A CTD line was then run westward (Fig. 5c) from the center of the gulf in parallel with El Puma's completion of the northern line.

The temperature structure in Fig. 5 reveals that the eddy was $\sim 120 \mathrm{~m}$ thick in its center. The northernmost CTD section (Fig. 5a) shows the general shape of the thermocline during the cruise: depressed in the west and elevated in the east. Near the eastern coast, the isotherms fan out vertically as they tilt downward nearshore. This warm northward flow of the Costa Rica Coastal Current carries with it the lowest-salinity surface water found anywhere in the gulf. In the center of the section $(150 \mathrm{~km})$, a small thermocline perturbation coincides with a cyclonic eddy evident in the satellite image and in ADCP vectors of 30 January (Fig. 3c).

The symmetric structure of the large eddy is revealed best by the SeaSoar run, which passed close to its center (Fig. 5b). The only asymmetry apparent is where high surface temperatures extend from the northern edge (left-hand side of the figure) into the center of the anticyclonic eddy as 
a result of entrainment of warm coastal waters from the west.

The third section (Fig. 5c), which passed just south of the eddy center parallel to the El Puma line (Fig. 5a), also shows the entrainment of warmer water into the eddy center. This warmer coastal water is easily identifiable in the El Puma section, where the same core of maximum temperature is evident. A corresponding warm tongue was seen in the imagery around these dates penetrating southeastward from the coastal region into the anticyclonic eddy.

\section{Fate of the Eddy}

Inspection of the complete satellite imagery sequence would suggest that the eddy was migrating offshore during the latter part of the cruise. Between 21 and 25 January, the eddy's southeastern boundary, marked by the region of maximum surface-temperature gradient, remained just north of the mooring position D2. However, in the subsequent period it moved considerably. There was an initial shift slightly to the northeast, after which (27 January to 7 February) the entire eddy moved away from the coast. The estimated direction of travel was $330^{\circ}$ and the speed was $\sim 10 \mathrm{~km} \mathrm{~d}^{-1}$. The appearance of several cusps along the western edge of the cool anomaly (during strong winds) is consistent with the existence of a series of eddies. If wind events follow each other rapidly, the eddy does not have time to migrate far from shore and will be reinforced by each event. With a longer interval between events the eddy may migrate far enough offshore that the next wind event will spin up a new eddy.

Hansen and Maul (1991) have documented the existence of anticyclonic eddies carried westward in the North Equatorial Current from an origin apparently near the eastern boundary of the Pacific Ocean. They concluded that these eddies formed through conservation of absolute vorticity as the North Equatorial Counter Current was diverted northward on reaching the coast of Central America. They ruled out the possibility of Tehuantepec or the Gulf of Papagayo (further south) as sources because the kinetic and available potential energies (KE and APE) of their eddies were higher than could be accounted for by short-lived wind events. They estimated KE and APE of 2.9 $\times 10^{15}$ and $4.1 \times 10^{15}$ Joules, respectively, for the observed eddies. Making use of their simple eddy model and substituting characteristic values from the Tehuantepec experiment, we find KE and APE of $\sim 1.3 \times 10^{15}$ and $1.0 \times 10^{15}$ Joules. The Tehuantepec eddy has considerably higher tangential velocities but similar pycnocline depression to Hansen and Maul's. The eddy diameter is only about one-half, hence the difference in energies.

Several reports (including: Strong et al., 1972; Stumpf and Legeckis, 1977; Leben et al., 1990) of westward propagation for eddies from the Tehuantepec region indicate that it may be a source for the type of eddies observed by Hansen and Maul. As noted earlier, widely separated wind events might generate a series of small anticyclonic eddies that dissipate rapidly. Frequent Norte events might form eddies that coalesce and spin up to the magnitude of those observed in the North Equatorial Current. The eddy reported here was largely spun up by a moderate wind event lasting $<3$ days. Two closely succeeding events of longer duration and greater magnitude could presumably spin up an eddy of the required $\mathrm{KE}$ and APE. At least one example of such an occurrence can be found in CZCS imagery, in which an anticyclonic eddy (of the size observed in 1989) is located inshore of another of twice the diameter.

\section{Concluding Remarks}

Our field work provides the first detailed in situ observations of the Gulf of Tehuantepec response to the intense but intermittent winter offshore winds. We have seen that the wind spreads after leaving the coast, rather than maintaining a narrow jet-like form, counter to the basic assumption of Clarke's (1988) model. The response to even a moderate wind event is dramatic and occurs within a day. The immediate response is strongest in the central Gulf, where surface temperatures drop by $\sim 8^{\circ} \mathrm{C}$ due to intense vertical mixing. Heat exchanges with the atmosphere do not play a major role during this cooling phase. When the strong offshore current jet and anticyclonic eddy develop, tongues of warm coastal and cooled central Gulf waters are advected around the periphery of the eddy. Upwelling and surface mixing of the warm, northward-flowing waters on the eastern, divergent flank of the wind result in shoaling and intensification of the stratification. On the western, convergent side of the wind, the pycnocline deepened to form an energetic anticyclonic eddy. Sinking of central Gulf mixed-layer waters, with enhanced chlorophyll levels, occurred down isopycnal surfaces beneath the eddy. Given a stronger wind event, or a close succession of events, the anticyclonic eddy could be sufficiently energetic to persist for a long period and to migrate out of the Gulf into the North Equatorial Current.

Although detailed comparison with model predictions is inappropriate here, some general comments may be made. The observed form of the wind jet during our experiment does not correspond to the coherent inertial jet supposed in Clarke's (1988) formulation. For even the average observed wind speed of $\sim 10 \mathrm{~m} \mathrm{~s}^{-1}$, the inertial radius would be $260 \mathrm{~km}$, twice that of the observed eddy. Moreover, the model indicated equal pycnocline depression and elevation to the west and east, respectively, of the wind, whereas the observations showed much greater deepening in the west than shoaling in the east. McCreary's (1989)

\section{Given a stronger}

wind event . . . the anticyclonic eddy could . . migrate . . into the North Equatorial Current. 
Little evidence was

found of a significant

cyclonic eddy . . . model agreed better with our observations. The upward motion of the pycnocline observed in the eastern Gulf seems to have been limited by intense vertical mixing, as in this model. Little evidence was found of a significant cyclonic eddy during the experiment, although circulation in the eastern Gulf was cyclonic in general terms. The inclusion of horizontal advection terms in the model produced a realistic "wrapping around" of warm and cold tongues on the periphery of the anticyclonic eddy, as was observed. The model predicts that the size of the eddy continues to expand, though in reality, subsequent wind events are likely to interfere with the development. A third model, developed by Trasviña (1991) since the experiment, utilizes two layers, a coastline, bottom topography, and a fan-shaped wind jet based on the observations. In this case, it was shown that realistic results could be obtained when the broad shelf to the east of the gulf was included. In particular, only a strong anticyclonic eddy developed. The model flow field was strikingly similar to that indicated by the mooring and ADCP data. No entrainment across the interface was included in this model.

The observed wind event was, fortunately, moderate in duration and intensity compared with others reported in the Gulf of Tehuantepec. More severe conditions would have curtailed our observations. In this report, only a sample of our data has been discussed. Many questions remain to be explored in detail. Why does no significant cyclonic eddy spin up? Is it because of suppression of the upwelled pycnocline by surface mixing? What is the importance of different shelf topography on either side of the Gulf? Can successive events enhance an existing anticyclonic eddy to the energy levels found in the North Equatorial Current vortices? What is the role of the smaller cyclonic gyres around the periphery of the anticyclone? Are they dissipating its energy or are they formed on the eastern Gulf and advected around the larger feature? What is the net effect on onshore-offshore exchange i.e., is there a significant offshore transport and renewal of coastal waters or merely recirculation? Some of these questions will be answered by the present data set but others will be resolved only by further modeling and field work.

\section{Acknowledgements}

We thank our colleagues on both ships who provided the support essential to carry out the field work. Thanks to Jeff Hawkins of NORDA, Stennis Space Center, Mississippi, who preprocessed the AVHRR imagery and forwarded anal- yses to the ships. We also thank Dave Enfield, NOAA-AOML, Miami, Florida, who provided daily weather forecasts for us at sea and contributed to the scientific discussions. Janice Chapman prepared the manuscript. This project was supported by the U.K. Natural Environment Research Council (Grant GR3/6719), the U.S. Office of Naval Research (Contracts N000 14-90-J-1177), the U.S. National Science Foundation (Grant OCE-9103034), and the Mexican Consejo Nacional de Ciencia y Tecnologia. The British Council provided funds for cooperation between the U.K. and Mexico (Grant 922/37).

\section{References}

Apel, J.R., 1980: Satellite sensing of ocean surface dynamics. Ann. Rev. Earth. Planet Sci, 8, 303-342.

Blackburn, M., 1962: An oceanographic study of the Gulf of Tehuantepec. US Fish Wild. Ser. Spec. Sci. Rept.-Fish., 404, 28.

Brown, J., E.D. Barton, A. Trasvin̄a, H.S. Velez Muñoz, P.M. Kosro and R.L. Smith 1992: Estimation of surface winds from upward looking Acoustic Doppler Current Profilers. J. Geophys. Res., 97, 17925-17930.

Clarke, A.. 1988: Inertial wind path and sea-surface temperature patterns near the Gulf of Tehuantepec and Gulf of $\mathrm{Pa}$ pagayo. J. Geophy's. Res., 93, 15491-15501.

Hansen, D. and G. Maul, 1991: Anticyclonic current rings in the Eastern Tropical Pacific Ocean. J. Geophys. Res., $95,6965-6979$.

Hurd, W.E., 1929: Northers of the Gulf of Tehuantepec. Mon W'a. Rev., 57, 192-194.

Lavín, M.F.. J.M. Robles, M.L. Argote, E.D. Barton, R. Smith. J. Brown. M. Kosro, A. Trasviña, H.S. Vélez Muñoz and J. García, 1992: Fisica del Golfo de Tehuantepec. Ciencia y Desarrollo, Vol XVIII, 103, 97-108.

Leben, R.R., J.D. Hawkins, H.E. Hurlburt and J.D. Thompson, 1990: Wind-driven anticyclonic eddies in the eastern equatorial Pacific Ocean. EOS, 71, 1364.

McCreary, J., H. Lee and D. Enfield, 1989: The response of the coastal ocean to strong offshore winds: with applications to the Gulf of Tehuantepec and Papagayo. $J$. Mar. Res., 47, 1.

Ramp, S.R., P.F. Jessen, K.H. Brink, P.P. Niiler, F.L. Daggett and J.S. Best, 1991: The physical structure of cold filaments near Point Arena. California during June 1987. J. Geophys. Res. 96, 14859-14883.

Roden, G.I., 1961: On the wind-driven circulation in the Gulf of Tehuantepec and its effect upon surface temperatures. Geofis. Int., 1, 55-72.

Strong, A.E., R.J. de Rycke and H.G. Stumpf, 1972: Satellite detection of upwelling and cold water eddies. Proc. $8 \mathrm{th}$ Int. Symp. Rem. Sens. Envir., Environmental Research Institute of Michigan Ann Arbor, 1067-1081.

Stumpf, H.G., 1975: Satellite detection of upwelling in the Gulf of Theuantepec, Mexico. J. Phys. Oceanogr.. 5, 383-388.

and R.V. Legeckis, 1977: Satellite observations of mesoscale eddy dynamics in the Eastern tropical Pacific Ocean. J. Phys. Oceanogr., 7, 648-658.

Trasviña Castro., A, 1991: Offshore wind forcing in a coastal ocean: observations and modelling of the Gulf of Tehuantepec, Mexico. Ph.D. thesis, University of Wales, 88pp. 